\title{
The Relationship between Family Stress and Internet Dependence: The Mediating Role of Loneliness-Empirical Analysis Based on CGSS2017
}

\author{
Kaibiao Xiang $\mathbb{D}^{1},{ }^{1}$ Huilin Song ${ }^{D},{ }^{1}$ and Zhenmin Cheng ${ }^{2}{ }^{2}$ \\ ${ }^{1}$ School of Management, Guizhou University, Guiyang, Guizhou 550025, China \\ ${ }^{2}$ School of Mathematics and Statistics, Guizhou University, Guiyang, Guizhou 550025, China \\ Correspondence should be addressed to Zhenmin Cheng; zmcheng@gzu.edu.cn
}

Received 30 September 2021; Accepted 6 December 2021; Published 18 February 2022

Academic Editor: Daqing Gong

Copyright (C) 2022 Kaibiao Xiang et al. This is an open access article distributed under the Creative Commons Attribution License, which permits unrestricted use, distribution, and reproduction in any medium, provided the original work is properly cited.

With the explosive development of modern technology, Internet dependence has become an important hindrance to normal use of the Internet. The influence of the family environment and individual perception has gradually emerged in practice, while the theoretical research is still insufficient yet. Therefore, to clarify the specific influence mechanism between them, we divided family stress into two dimensions in this study, which are behavioral stress and emotional stress. Furthermore, combined with individual loneliness, a theoretical framework of the mediating effect is constructed to confirm the influence of family stress on Internet dependence and explore its action path and mechanism. Based on the data of CGSS2017, the empirical research shows that both behavioral and emotional stress from family can significantly increase the degree of Internet dependence of individuals and individual loneliness plays a partial mediating role between family stress and degree of Internet dependence. The results of this study provide powerful theoretical proof for practical experience and also provide a possible way of solving problems with Internet dependence in practice.

\section{Introduction}

Nowadays, with the rapid development of Internet technology, the number of Internet users in China is increasing year by year, and the youth group is almost saturated. The Statistical Report on Internet Development in China released by China Internet Network Information Center (CNNIC) shows that as of June 2019, the number of Internet users in China reached 854 million, and the penetration rate reached $61.2 \%, 1.6$ percentage points higher than that at the end of 2018 [1]. However, while the Internet brings unprecedented convenience, Internet dependence, as a new addiction phenomenon, has attracted widespread attention [2]. Different from Internet addiction, Internet dependence refers to a kind of mild excessive Internet using behavior, between normal Internet using and addiction. Internet users who tend to Internet dependence maybe do not show typical symptoms of addiction, but psychologically rely on the
Internet $[3,4]$. It not only weakens the positive effect of technological development on individuals but also brings great negative impact on the normal progress of work, study, and other real life. Internet dependence has increasingly become a national problem $[5,6]$. However, how to reduce the probability and the degree of Internet dependence have not been fully studied and solved.

Based on existing studies about Internet dependence, we found two parts that are obviously weak. On the one hand, current research mostly focuses on middle school students and college students [7]. One of the reasons of that is the young group is the dominant part of the group with Internet dependence in the past. Moreover, this phenomenon is also out of society's inherent concern for teenagers. Therefore, a big question emerging is that the impact on off-campus personnel is overlooked. These group having an obvious limitation of spare time and leisure time because of working, thus their time spent on the Internet may be relatively 
smaller than the young. However, they have greater social pressures from lot of aspects, which will creates an incentive to be dependent on the Internet to escape the stressful reality. The virtual world could give them a shelter without pressure but indulging in it also brings negative effect on their normal life both in behavior and psychology. According to the above discussion, Internet dependence should be regarded as a common problem related to the whole society instead of being limited to a specific group like students. On the other hand, although the majority of researches agree that external pressure and individual feeling are important factors leading to Internet dependence $[8,9]$, most of studies only focus on one of the two. However, under such research frameworks, it is difficult to give comprehensive consider to the issue, and also having some problems to apply to practice. So combining the above two points, this article introduces family pressure and individual feelings into the theoretical model simultaneously at same time and expands to the whole age in terms of the research object.

\subsection{Theoretical Basis and Research Hypothesis. According to} social support theory, one's social needs have been met from interpersonal relationships [10], in which family and relatives are extremely important parts. Low social support from them means a lack of supportive relationships or even a lot of negative relationships [11]. Social support can influence Internet addiction to a high level [12], for that lacking of social support would make individuals turn to Internet for virtual support, and Internet dependence even Internet addiction is a potential consequence $[13,14]$.

This article regards the formation of Internet dependence as a two-stage process: the first stage is the inner feeling, and the second one is the behavior manifestation. Therefore, the theoretical framework is also divided into two parts: one part analyzes the Internet dependence caused by the behavioral interference of relatives and emotional stress, and the other part analyzes the Internet dependence caused by the family stress that leads to the increase of individuals' loneliness and then seeks recognition from the cyberspace.

1.2. Family Stress and Internet Dependence. Internet dependence is different from pathological Internet addiction and is a psychological dependence phenomenon between normal Internet access and Internet addiction [15]. This dependence is mediated by the network and is relied on virtual substances such as network interaction experience and network information, making individuals use the Internet excessively, thereby affecting their normal life, study, and work [16]. For example, long periods of separation from the real world can lead to impairment of physiological, social, and psychological functions [17].

The family is the most enduring and important system for individual development [18]. Peng and Zhou [19] suggest that excessive parental interference, protection, rejection, or punishment would make the children generate the tendency of Internet independence. There is a significant positive correlation between parental overprotection and intervention and
Internet dependence, which is a predictor of Internet dependence [20]. Some scholars believe that the degree of family relation harmony, the degree of parental discipline, and the communication methods between family members will affect the use of the Internet by family members, especially young individuals [21, 22]. For example, if family members often express negative emotions, individuals may feel isolated, neglected, and other negative feelings in their family, thus increasing the likelihood and severity of Internet dependence. Family stress can be reflected by the rigid demands of relatives and friends, the substantial intervention, and the intangible emotional pressure of family members. Therefore, this article proposes the following assumptions:

H1: the greater the family pressure, the higher the individual Internet dependence.

H1a: the more family behavior interventions, the higher the degree of Internet dependence.

H1b: the more family and friends you ask for, the more Internet dependence you have.

H1c: the greater the family emotional stress, the higher the individual Internet dependence.

1.3. Family Stress and Loneliness. According to the Social Needs Theory, social connections is an inherent need for individuals. And if it is not been well met, loneliness will sets in as a result [23]. Due to the emphasis on the sense of belonging of groups, especially family groups in Chinese cultural background, the family environment is more likely to have a greater impact on the sense of loneliness of individuals [24, 25]. According to ecosystem theory, the family and its peers are the two major social systems that affect the development of individuals [26], with important implications for it in many ways [27]. For individuals, the family is the environment that provides the basic living and development conditions. All aspects of the family will directly affect the physical and mental development of each of its members [28]. The support of families and friends can significantly decrease loneliness, especially emotional support was more effective in this process [29]. If there are more excessive interference and control behaviors in family, the children's will be relatively fixed, lack initiative, and more inclined to carry out self-denial forming the character characteristics of low self-esteem and low self-confidence and social anxiety [30], thus producing a stronger sense of loneliness. The request and intervention of relatives and friends will make individuals unable to obtain the recognition and benign attention from the family. At the same time, they lack the accurate cognition of self-consciousness. Therefore, this article proposes the following assumptions:

H2: the greater the family pressure, the stronger the sense of loneliness.

H2a: the more family behavior intervention, the stronger the loneliness of individuals.

H2B: the more family and friends you ask for, the more lonely you feel. 
H2c: the greater the family emotional pressure, the stronger the loneliness of individuals.

1.4. Loneliness and Internet Dependence. Loneliness is a negative character trait, a subjective negative experience or feeling appearing when an individual is not satisfied with his own interpersonal relationship or interpersonal communication, or when there is a gap between the expected level of interpersonal communication and the actual level of interpersonal communication [31]. Good interpersonal relationships can provide social support for individuals [32]. Maintaining proper relationships with people, society, and nature around an individual is not only conducive to the individual's own growth but also conducive to the individual's psychological health, emotional stability, and positive emotional experience [33]. Negative personality traits and emotions, such as high boredom, loneliness, social anxiety, and self-isolation, all have significant effects on the occurrence of Internet dependence [34, 35]. In the research on personality characteristics, mental health, and Internet dependence of college students, it is also found that there was a significant relationship between the loneliness or other negative emotional fluctuation and Internet dependence [36]. Since then, these relationships have been confirmed by regression analysis, and the depression is a predictor of Internet dependence [37]. Netizens generally tend to believe that making friends and social groups on the Internet can make them feel supported and recognized to some extent, thereby achieving the effect of relieving loneliness [38]. Therefore, this paper proposes the following assumptions:

H3: the stronger the loneliness, the higher the degree of Internet dependence.

1.5. Mediation Effect of Family Stress, Loneliness, and Internet Dependence. Family stress belongs to the external environment of the family, which needs to go through a certain process of perception. Individuals with close and equal family ties tend to be optimistic and positive, more used to choose direct communication for emotional counseling and problem resolution when problems arise, and less need to rely on virtual Internet for attention, recognition, and relaxation [39]. On the contrary, individuals with high family pressure often lack a social support system, and their negative emotions are difficult to pour out and dispelled at the same time, so they tend to reduce their troubles by virtue of network products such as games and information flow. This increases the possibility of Internet dependence. According to the above theoretical analysis, three aspects of family pressure-behavioral intervention, demands from relatives or friends, and emotional pressure-will affect individuals' perception, thus enhancing or alleviating individuals' loneliness, and ultimately affecting the formation of Internet dependence behavior.

According to the research hypothesis of the above theoretical analysis, the theoretical model as shown in Figure 1 is obtained in this study.

\section{Materials and Methods}

2.1. Data Source. The data used in this paper are from China General Social Survey CGSS2017. CGSS is the earliest national, comprehensive, and continuous academic survey project in China. It is jointly conducted by China Survey and Data Center of Renmin University of China. The data cover a wide range, are open and shared, and have become one of the most widely used survey data in Chinese society. The survey data of CGSS2017 were officially released on October 1, 2020 , with a total of 12,582 valid samples containing 783 variables. The questionnaire consists of three modules $\mathrm{A}, \mathrm{C}$, and D. After screening useless samples such as missing values and unanswerable samples, the number of remaining samples is 2246 .

\subsection{Variable Setting and Reliability and Validity Analysis.} The measurement and coding of variables in this paper are shown in Table 1 . The main variables are the degree of Internet dependence, behavioral intervention, demands from relatives and friends, emotional stress, and loneliness. The data are all from the CGSS2017 survey, in which the three continuous variables DE, SL, and AGE are treated with $5 \%$ level tail reduction.

In this article, the variables constituted by multiple items include Internet dependence degree (DE) and sense of loneliness degree (SL). Cronbach' $\alpha$ and combined reliability of both of them are greater than 0.8 , and KMO value is 0.851 , indicating good reliability and validity of the model. Specific data are shown in Table 2.

\section{Results and Discussion}

An empirical analysis IN this paper, the idea is as follows: first of all, to verify the independent variable behavior intervention (IN) requirements (RE), emotional stress, relatives and friends (EM) on the dependent variable network dependent (DE), and then verify the independent variable on the role of intermediary variable loneliness (SL) is significant, the final inspection complete mediation effect model is established.

Table 3 reports the mean, standard deviation, and correlation matrix of all variables in this study. According to the results of descriptive statistics, there is a significant correlation between the independent variables IN, RE, EM, the mediating variable SL, and the dependent variable DE, and the direction of the correlation coefficient is consistent with the hypothesis, which preliminarily indicates that the hypothesis has a strong rationality. Meanwhile, in order to avoid the impact of multicollinearity on the regression results, this paper checked the VIF values of the regression, which were all less than 2 . Therefore, there was no serious multicollinearity in the regression model.

Table 4 reports the results of empirical testing of the hypothesis. Model 1 and Model 2 verify the relationship between dependent variables and independent variables. Model 1 contains all the control variables, and Model 2 adds three dependent variables on the basis of it. The results of 


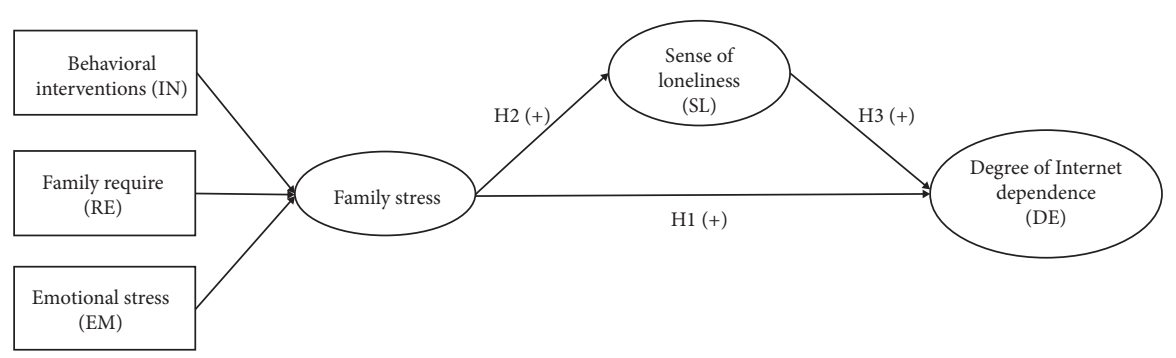

Figure 1: Theoretical model of this paper.

TABLe 1: Variable measurement and coding.

\begin{tabular}{|c|c|c|c|}
\hline Variable types & Variable name & Items & Calculation \\
\hline $\begin{array}{l}\text { Dependent } \\
\text { variables }\end{array}$ & $\begin{array}{l}\text { Degree of internet } \\
\text { dependence (DE) }\end{array}$ & $\begin{array}{l}\text { DE1. Compared with before, I spend more and } \\
\text { more time on the internet } \\
\text { DE2. When I feel in a bad mood, I surf the } \\
\text { internet so that I can feel better } \\
\text { DE3. I Often spend more time on the internet } \\
\text { than I plan to } \\
\text { DE4. Because of the internet, my daily life has } \\
\text { been affected } \\
\text { DE5. My work is affected by surfing the internet } \\
\text { DE6. Because of the internet, I have become } \\
\text { more distant from the people around me } \\
\text { DE7. I Get antsy if I do not use the internet for a } \\
\text { while } \\
\text { DE8. Because of the internet, I have less and less } \\
\text { time to go out for activities } \\
\text { DE9. Because of the internet, my eyesight is } \\
\text { getting worse } \\
\text { DE10. Because of the internet, my shoulders } \\
\text { and neck ache } \\
\text { DE11. My family complains that I spend too } \\
\text { much time on the internet }\end{array}$ & $\begin{array}{l}\text { Each item is assigned a value according to the } \\
\text { results of CGSS2017 questionnaire, "very } \\
\text { disagrees" = 1, "relatively disagrees" = 2, "no } \\
\text { agreement or disagrees" = 3, "relatively } \\
\text { agrees" = 4, "very agrees" }=5 \text {, and the final } \\
\text { variable value is obtained by summation }\end{array}$ \\
\hline \multirow{3}{*}{$\begin{array}{l}\text { Independent } \\
\text { variables }\end{array}$} & $\begin{array}{c}\text { Behavioral } \\
\text { interventions (IN) }\end{array}$ & $\begin{array}{l}\text { In general, do you get pressure from your } \\
\text { family IN terms of your lifestyle or your private } \\
\text { living arrangements (pressure here means not } \\
\text { letting you do things or insisting that you do } \\
\text { things they want you to do)? }\end{array}$ & $\begin{array}{l}\text { According to the results of the CGSS2017 } \\
\text { questionnaire, "no, never" = 1, "yes, but } \\
\text { rarely" = 2, "yes, sometimes" }=3 \text {, "yes, often" }=4 \text {, } \\
\text { "yes, very often" = } 5\end{array}$ \\
\hline & Family require (RE) & $\begin{array}{l}\text { Do you feel that your family, relatives, and/or } \\
\text { friends often ask too much of you? }\end{array}$ & $\begin{array}{l}\text { According to the results of the CGSS2017 } \\
\text { questionnaire, "no, never" = } 1 \text {, "yes, but } \\
\text { rarely" }=2 \text {, "yes, sometimes" }=3 \text {, "yes, often" }=4 \text {, } \\
\text { "yes, very often" }=5\end{array}$ \\
\hline & $\begin{array}{l}\text { Emotional stress } \\
(\mathrm{EM})\end{array}$ & $\begin{array}{l}\text { Think about the significant people in your life, } \\
\text { such as your spouse or common-law partner, } \\
\text { family, or close friends. Have they been angry } \\
\text { or disappointed with you in the last four weeks? }\end{array}$ & $\begin{array}{l}\text { According to the results of the CGSS2017 } \\
\text { questionnaire, "never" = 1, "rarely" = 2, } \\
\text { "sometimes" = 3, "often" = 4, "very often" = } 5\end{array}$ \\
\hline $\begin{array}{l}\text { Intervening } \\
\text { variable }\end{array}$ & $\begin{array}{l}\text { Sense of loneliness } \\
\text { (SL) }\end{array}$ & $\begin{array}{l}\text { SL1. Feeling lack of company } \\
\text { SL2. Feeling isolated from others }\end{array}$ & $\begin{array}{l}\text { The questions were based on the CGSS2017 } \\
\text { questionnaire "in the past four weeks, how often } \\
\text { have you felt like this?" select the values, } \\
\text { "never" = } 1 \text {, "rarely" = } 2 \text {, "sometimes" = } 3 \text {, } \\
\text { "often" = 4, "very often" = 5, and take the mean } \\
\text { value to get the final variable value }\end{array}$ \\
\hline
\end{tabular}


TABle 1: Continued.

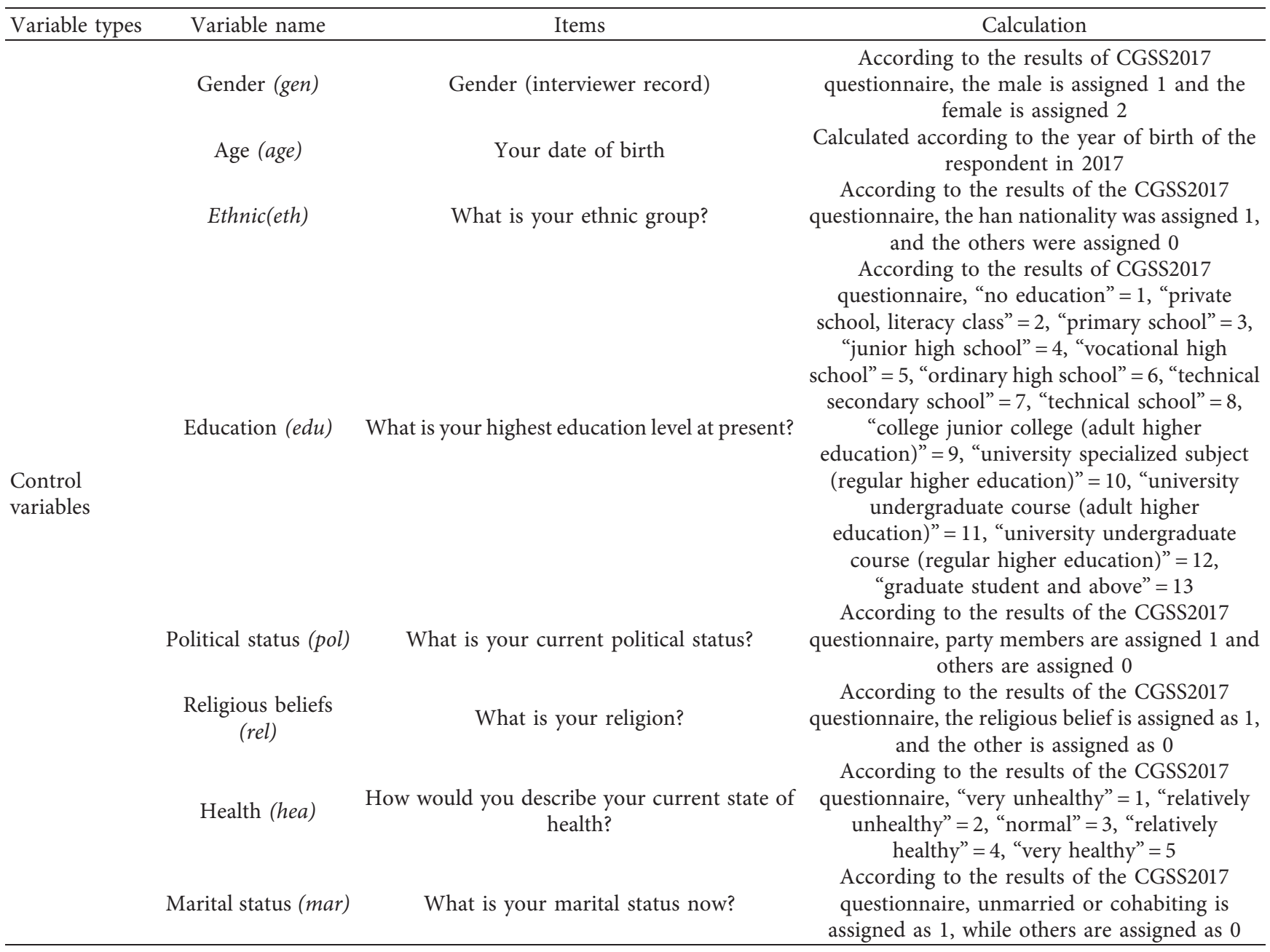

TABLE 2: Reliability and validity analysis of variables.

\begin{tabular}{lcccc}
\hline Variables & Items & Cronbach's $\alpha$ & CR & AVE \\
\hline \multirow{4}{*}{ DE1 } & & & \\
& DE2 & & & \\
& DE3 & & & \\
& DE4 & & & \\
& DE5 & & 0.89 & 0.43 \\
DE & DE6 & 0.866 & & \\
& DE7 & & & \\
& DE8 & & & \\
& DE9 & & & \\
& DE10 & & & \\
& DE11 & & & \\
& SL1 & & & \\
SL & SL2 & 0.963 & & \\
& SL3 & & & \\
& & & & \\
\hline
\end{tabular}

Model 2 showed that there was a significant positive correlation between behavioral intervention and the degree of Internet dependence (Beta $=0.701, p<0.01)$. Hypothesis $1 \mathrm{a}$ was true. There was a significant positive correlation between the demands of relatives and friends and the degree of Internet dependence (Beta $=0.834, p<0.01)$. Hypothesis $1 \mathrm{~b}$ was true. There was a significant positive correlation between emotional stress and the degree of Internet dependence (Beta $=0.716, p<0.01)$. Hypothesis $1 \mathrm{c}$ was valid, so $\mathrm{Hy}$ pothesis 1 was verified. Family pressure can significantly affect an individual's degree of Internet dependence. The more family pressure an individual feels, the higher his or her degree of Internet dependence is.

Model 4 and Model 5 verify the relationship between family stress and loneliness. Model 4 is the baseline model, and Model 5 is the full model. According to the results of Model 5, there is a significant positive correlation between behavioral intervention and individual loneliness (Beta $=0.126, p<0.01)$. Hypothesis $2 \mathrm{a}$ is true. There was a significant positive correlation between the demands of relatives and friends and loneliness (Beta $=0.066, p<0.01$ ). Hypothesis $2 \mathrm{~b}$ was true. There was a significant positive correlation between emotional stress and individual loneliness (Beta $=0.187, p<0.01$ ). Hypothesis $2 \mathrm{C}$ was valid, and Hypothesis 2 was verified. Family pressure has a significant impact on individual loneliness. The greater the family pressure, the stronger the feeling of loneliness.

Model 3 added variable loneliness on the basis of Model 2 and verified the total effects of independent variables and mediating variables on dependent variables. The results of 


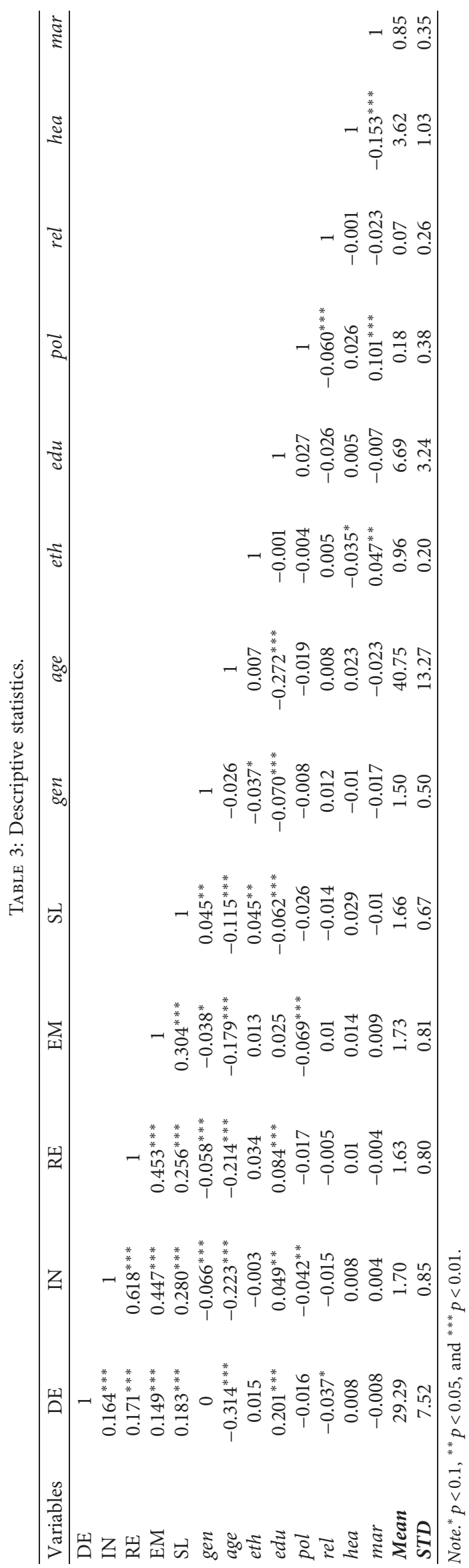


TABLe 4: Test of the relationship between family stress, sense of loneliness, and the degree of Internet dependence.

\begin{tabular}{|c|c|c|c|c|c|}
\hline \multirow{2}{*}{ Variables } & \multicolumn{3}{|c|}{ Internet dependence (DE) } & \multicolumn{2}{|c|}{ Sense of loneliness (SL) } \\
\hline & Model 1 & Model 2 & Model 3 & Model 4 & Model 5 \\
\hline Behavioral interventions (IN) & & $0.389^{* * *}(0.230)$ & $0.223(0.230)$ & & $0.110^{* * *}(0.020)$ \\
\hline Family require (RE) & & $0.498^{* *}(0.244)$ & $0.401^{*}(0.242)$ & & $0.064^{* * *}(0.022)$ \\
\hline Emotional stress (EM) & & $0.531^{* *}(0.214)$ & $0.279(0.216)$ & & $0.167^{* * *}(0.019)$ \\
\hline Sense of loneliness (SL) & & & $1.509^{* * *}(0.236$ & - & - \\
\hline Gender (gen) & $0.030(0.301)$ & $0.165(0.299)$ & $0.044(0.297)$ & $0.0484^{*}(0.028)$ & $0.080^{* * *}(0.027)$ \\
\hline Age (age) & $-0.159^{* * *}(0.012)$ & $-0.141^{* * *}(0.012)$ & $-0.137^{* * *}(0.012)$ & $-0.007^{* * *}(0.001)$ & $-0.003^{* * *}(0.001)$ \\
\hline Ethnic (eth) & $0.694(0.753)$ & $0.606(0.748)$ & $0.379(0.742)$ & $0.165^{* *}(0.070)$ & $0.150^{* *}(0.066)$ \\
\hline Education $(e d u)$ & $0.289^{* * *}(0.049)$ & $0.291^{* * *}(0.048)$ & $0.320^{* * *}(0.048)$ & $-0.020^{* * *}(0.005)$ & $-0.019^{* * *}(0.004)$ \\
\hline Political status $(p o l)$ & $-0.508(0.396)$ & $-0.361(0.394)$ & $-0.352(0.390)$ & $-0.047(0.037)$ & $-0.006(0.035)$ \\
\hline Religious beliefs ( $\mathrm{rel}$ ) & $-0.962^{* * *}(0.583)$ & $-0.948(0.579)$ & $-0.881(0.574)$ & $-0.047(0.054)$ & $-0.044(0.051)$ \\
\hline Health (hea) & $0.100(0.148)$ & $0.081(0.146)$ & $0.054(0.145)$ & $0.023(0.014)$ & $0.018(0.013)$ \\
\hline Marital status (mar) & $-0.217(0.432)$ & $-0.230(0.429)$ & $-0.198(0.425)$ & $-0.016(0.040)$ & $-0.021(0.038)$ \\
\hline Constant & $33.126^{* * *}(1.311)$ & $29.919^{* * *}(1.404)$ & $28.390^{* * *}(1.412)$ & $1.795^{* * *}(0.123)$ & $1.013^{* * *}(0.125)$ \\
\hline The $\mathrm{F}$ value & $36.41^{* * *}$ & $30.33^{* * *}$ & $31.70^{* * *}$ & $8.12^{* * *}$ & $32.40^{* * *}$ \\
\hline The adjusted R2 & 0.112 & 0.126 & 0.141 & 0.025 & 0.133 \\
\hline Observations & 2246 & 2246 & 2246 & 2246 & 2246 \\
\hline
\end{tabular}

Note. ${ }^{*} p<0.1,{ }^{* *} p<0.05$, and ${ }^{* * *} p<0.01$. The parentheses are reported as standard errors.

Model 3 showed that the influence of behavioral intervention, demands of relatives and friends, and emotional stress on the degree of Internet dependence were still significant, but compared with Model 2, the significance of behavioral intervention and emotional stress was decreased (Beta $=0.499, p<0.05 ;$ Beta $=0.73, p<0.01$; Beta $=0.418$, $p<0.1$ ), and there was a significant positive correlation between loneliness and Internet dependence (Beta $=1.598$, $p<0.01)$. Hypothesis 3 was verified. The more lonely an individual feels, the more dependent he or she is on the Internet. From the above analysis results, it can be seen that family stress can enhance the degree of Internet dependence of individuals by positively affecting loneliness, and it can also directly have a significant positive impact on the degree of Internet dependence. Loneliness plays a partial mediating role between family stress and Internet dependence, and Hypothesis 4 is verified.

\section{Conclusions}

Family pressure on family members plays an important role for personal growth, by influencing the mental state and behavior cultivation. According to the findings and shortcomings of existing literature, this paper constructs a theory model about the emergence and degree of Internet dependence, including internal factors and behavioral manifestation, and confirms the related theory assumed the by empirical test. The empirical results accord with theoretical expectations, and specific findings are as follows.

First, the pressure that an individual feels on his or her family can significantly improve the degree of Internet dependence of him or her. The pressure from the family will make one have a weaker sense of freedom and a stronger sense of bondage during growth. On the one hand, this will lead to weak willpower, resulting in that the individual is prone to be attracted by the instant pleasure brought by the Internet and then excessively addicted to the Internet. On the other hand, it will lead to dissatisfaction with real life and psychological pressure. So there is more potential to seek freedom and relaxation from the Internet, which means dependence.

Second, among the three manifestations of family stress, emotional stress has the greatest impact on Internet dependence, followed by behavioral interference. Tangible intervention and requirements are more clear for individuals and thus easier to release through self-persuasion or resistance. Moreover, in the face of these two types of family pressure, individuals are more inclined to attribute their negative emotions to surroundings, which will have little impact on the individual's self-cognition and self-evaluation, thus reducing the possibility of eventual Internet dependence behavior through internal negative emotions. On the contrary, the disappointment and anger of others exert direct pressure on the individual's emotion, which is more difficult to detect and treat rationally. Individuals will have negative self-examination and evaluation behaviors in the face of emotional pressure, resulting in feelings such as selfaccusation and anxiety, which will have a more serious negative impact compared with behavioral intervention. This view is also verified in Model 5. Among the three dimensions of family stress, emotional stress has the largest influence on loneliness, that is, emotional stress is more likely to have a negative impact on self-recognition.

Third, individual loneliness will significantly promote the emergence of Internet-dependent behavior and increases the degree of dependence. Internet community, as well as the rapid development of the community, gives individuals more chance to find others having the same idea with themselves, getting recognition, and support. Individuals with smaller social scope and less social support are easier to use online communities for getting approval. As well as when one feel depressed, he will also rely on the Internet to ease and express himself. Correspondingly, more social support in reality is beneficial to reduce the loneliness of individuals and thus reduce their possibility of Internet dependence. 
Fourth, in terms of individual heterogeneity of gender, there is no significant difference in the degree of Internet dependence. But women are more likely to have a strong sense of loneliness compared with men, and family pressure will also be transformed into the inner feeling of loneliness at a higher level. In terms of age characteristics, the older the individuals are, the more mature and stable their self-cognition and evaluation, the less affected by external pressure, finally the less dependent they are on the Internet. Compared with age, educational background more significantly reduces the level of loneliness. In other words, with the improvement of education, individuals will have more sources of social support network. The improvement of knowledge and vision will establish a clearer self-cognition for them, and they will be less affected by external pressure. However, while educational background significantly reduces loneliness, it also has a significant positive effect on the degree of Internet dependence, which means that individuals with higher educational background have other influencing mechanisms in the generation of Internet dependence. They are more likely to rely on the Internet for other needs rather than seeking virtual recognition, such as satisfying entertainment, relieving academic stress, or exploring different lives.

Finally, in terms of practical significance, our findings provide a solution of Internet dependence based on the perspective of individual feeling. The mediation of loneliness between family pressure and Internet dependence suggests the importance of individual feeling and a possibility of work along both lines, including external pressure and internal perception. In this way, we should not only focus on the environment but should also pay attention to psychological mechanism. Therefore, under a negative and stressful environment that almost impossible to change, our finding suggests that adjusting the way of thinking from the negative to positive could help to alleviate the risk of Internet dependence.

Due to the limitations of the existing secondary data, this study still has the following shortcomings: the mediator variables between family stress and individual network are not fully mined, and there may be some undiscovered mediator variables and logical relationship; due to the limitation of questionnaire items, the measurement of psychological status and family pressure is not comprehensive and complete enough. In future studies, a more mature and complete scale can be used to more accurately reflect the research variables and build a more convincing, multilevel, and multifaceted relationship model.

\section{Data Availability}

The data used to support the findings of this study are available from the corresponding author upon request.

\section{Conflicts of Interest}

The authors declare that there are no conflicts of interest regarding the publication of this paper.

\section{Acknowledgments}

This work was supported by the program of Philosophy and Social Science of GuiZhou Province under Grant nos. 19GZYB71 and 21GZYB11.

\section{References}

[1] China Internet Network Information Center (CNNIC), The 44th Statistical Report on China's Internet Development in 2019, China Internet Network Information Center. (CNNIC), Beijing, China, 2019.

[2] Z. Qian, F. Lei, and G. Zhang, "Research status of adolescent internet addiction," China General Practice, vol. 23, no. 13, pp. 1687-1694, 2020.

[3] B. L. Fortson, J. R. Scotti, Y. C. Chen, J. Malone, and K. S. Del Ben, "Internet use, abuse, and dependence among students at a southeastern regional university," Journal of American College Health, vol. 56, no. 2, pp. 137-144, 2007.

[4] Z. Huang, M. Y. Qian, Y. I. Chun-Li, J. Nie, and J. Deng, "Correlated factors comparison: the trends of computer game addiction and internet relationship addiction," Chinese Journal of Clinical Psychology, vol. 14, no. 3, pp. 244-247, 2006.

[5] L. Cerniglia, F. Zoratto, S. Cimino, G. Laviola, M. Ammaniti, and W. Adriani, "Internet Addiction in adolescence: neurobiological, psychosocial and clinical issues,psychosocial and clinical issues," Neuroscience \& Biobehavioral Reviews, vol. 76, no. Pt A, pp. 174-184, 2017.

[6] L. Cerniglia, "Brief considerations on internet use in adolescence," EC Psychology and Psychiatry, vol. 5, no. 1, pp. 10-11, 2017.

[7] B. Zhou, "Netizens' internet psychological dependence, alienation from reality and self-redemption," Jianghuai Forum, vol. 305, no. 1, pp. 147-152, 2021.

[8] A. M. Saikia, J. Das, P. Barman, and M. D Bharali, "Internet addiction and its relationships with depression, anxiety, and stress in urban adolescents of kamrup district, Assam," Journal of family \& community medicine, vol. 26, no. 2, pp. 108-112, 2019.

[9] W. Cui, X. Yan, and A. Zheng, "The relationship between college students' self-identity and internet addiction: the moderating role of subjective well-being," Journal of Nan Jing Medical University, vol. 15, no. 4, pp. 293-297, 2015.

[10] A. Vaux, J. Phillips, L. Holly, B. Thomson, D. Williams, and D. Stewart, "The social support appraisals (ss-a) scale: studies of reliability and validity," American Journal of Community Psychology, vol. 14, no. 2, pp. 195-218, 1986.

[11] J. C. Coyne and G. Downey, "Social factors and psychopathology: stress, social support, and coping processes," Annual Review of Psychology, vol. 42, no. 1, pp. 401-425, 1991.

[12] X. Chu, Y. Li, P. Wang, P. Zeng, and L. Lei, "Social support and cyberbullying for university students: the mediating role of internet addiction and the moderating role of stress," Current Psychology, vol. 40, 2021.

[13] R. A. Davis, "A cognitive-behavioral model of pathological internet use," Computers in Human Behavior, vol. 17, no. 2, pp. 187-195, 2001.

[14] D. Kardefelt-Winther, “A conceptual and methodological critique of internet addiction research: towards a model of compensatory internet use," Computers in Human Behavior, vol. 31, pp. 351-354, 2014.

[15] X. L. Wu and C. Q. Xu, "Internet-dependence among college students," China Adult Education, vol. 13, pp. 127-129, 2014. 
[16] W. B. Gao and Z. Y. Chen, "Study on the pathophysiological mechanism and comprehensive psychological intervention of Internet addiction," Advances in Psychological Science, vol. 4, pp. 596-603, 2006.

[17] G. Z. Feng, "An Analysis of College Students' Internet Dependence Behavior and its Causesm," M.A. Thesis, Wuhan University of Technology, Wuhan, China, 2004.

[18] U. Bronfenbrenner, "Toward an experimental ecology of human development," American Psychologist, vol. 32, no. 7, pp. 513-531, 1977.

[19] Y. Peng and S. Zhou, "Relationship of internet addiction and family environment and parental rearing patterns in adolescents," Chinese Journal of Clinical Psychology, vol. 15, no. 4, pp. 418-419+ 439, 2007.

[20] Y. L. Chen, S. H. Chen, and S. S. F. Gau, "Adhd and autistic traits, family function, parenting style, and social adjustment for internet addiction among children and adolescents in taiwan: a longitudinal study," Research in Developmental Disabilities, vol. 39, no. 39, pp. 20-31, 2015.

[21] D. T. L. Shek, Q. Xie, and L. Lin, "The impact of family intactness on family functioning, parental control, and Parentâ€"Child relational qualities in a Chinese context," Frontiers in Pediatrics, vol. 2, p. 149, 2014.

[22] D. T. L. Shek and L. Yu, "Adolescent internet addiction in Hong Kong: prevalence, change, and correlates," Journal of Pediatric and Adolescent Gynecology, vol. 29, no. 1, pp. S22-S30, 2016.

[23] K. J. Rotenberg and S. Hymel, Loneliness in Childhood and Adolescence, Cambridge University Press, Cambridge, UK, 1999.

[24] D. Zhou and Y. F. Bian, X. Y. Chen, The influence and difference of father's and mother"s warm parenting styles on loneliness of junior middle school students," China Special Education, vol. 189, no. 3, pp. 64-70, 2016.

[25] F. O. Ozturk, M. Ekinci, O. Ozturk, and F. Canan, “The relationship of affective temperament and emotional-behavioral difficulties to internet addiction in Turkish teenagers," Isrn Psychiatry, vol. 2013, no. 3, Article ID 961734, 2013.

[26] U. Bronfenbrenner, The Ecology of Human Development, Harvard University Press, Cambridge, MA, USA, 1979.

[27] J. Yan, X. Feng, and S. J. Schoppe-Sullivan, "Longitudinal associations between parent-child relationships in middle childhood and child-perceived loneliness," Journal of Family Psychology, vol. 32, no. 6, pp. 841-847, 2018.

[28] J. Zheng, "The Relationship between College Students' Family Environment, Positive Personality and Internet Dependence," M.A. Thesis, Hebei Normal University, Shijiazhuang, China, 2011.

[29] I. Hombrados-Mendieta, M. García-Martín, and L. GómezJacinto, "The relationship between social support, loneliness, and subjective well-being in a Spanish sample from a multidimensional perspective," Social Indicators Research, vol. 114, no. 3, pp. 1013-1034, 2013.

[30] T. Dehart, B. W. Pelham, and H. Tennen, "What lies beneath: parenting style and implicit self-esteem," Journal of Experimental Social Psychology, vol. 42, no. 1, pp. 1-17, 2006.

[31] C. Y. Li, "An analysis of college students' loneliness," Journal of Zibo College (Social Science Edition), vol. 3, pp. 75-76, 1998.

[32] Y. Shao, S. Xu, and J. Chen, "Internet addiction in adolescent adolescence," Chinese Journal of School Health, vol. 41, no. 2, pp. 316-320, 2020.

[33] M. Seeman, "The signals of 68: alienation in pre-crisis France," American Sociological Review, no. 4, pp. 385-402, 1972.
[34] I. Taş, “Association between depression, anxiety,stress,social support,resilience and internet addiction: a structural equation modelling," Malaysian Online Journal of Educational Technology, vol. 7, no. 2, pp. 1-10, 2019.

[35] C. S. Ang, N. N. Chan, and C. S. Lee, "Shyness, loneliness avoidance, and internet addiction: what are the relationships?" Journal of Psychology, vol. 152, no. 1, pp. 25-35, 2018.

[36] C. H. Ko, J. Y. Yen, C. F. Yen, C. S. Chen, and C. C. Chen, "The association between Internet addiction and psychiatric disorder: a review of the literature," European Psychiatry, vol. 27, no. 1, pp. 1-8, 2012.

[37] C. M. Morrison and H. Gore, "The relationship between excessive internet use and depression: a questionnaire-based study of 1,319 young people and adults," Psychopathology, vol. 43, no. 2, pp. 121-126, 2010.

[38] S. D. Neverkovich, I. S. Bubnova, N. N. Kosarenko et al., "Students' Internet addiction: study and prevention," Eurasia Journal of Mathematics, Science and Technology Education, vol. 14, no. 4, pp. 1483-1495, 2018.

[39] Y. Luo and X. Zhang, "The family environment of adolescent with internet addiction," Chinese Journal of Health Psychology, vol. 18, no. 2, pp. 243-244, 2010. 